\title{
Teenagers anthropometric measurement and furniture mismatchment
}

\author{
SANDHYA N. ADMANKAR AND H.L. SARAMBEKAR
}

Received: 04.12.2014; Revised: 29.03.2015; Accepted: 14.04.2015

See end of the paper for authors' affiliations SANDHYA N. ADMANKAR Department of Family Resource Management, College of Home Science, Vasantrao Naik Marathwada Krishi Vidyapeeth, PARBHANI (M.S.) INDIA

Email : admankar.sandhya@ rediffmail.com
ABSTRACT : In the varied spheres of life various anthropometric mismatches are seen but are unknowingly being used and the physical problems arising from these are treated as if they were due to some medical problems, for example the height of some counters are such that interactions between the man behind the counter and visitor are obstructed. Writing stands, counter plat forms, which are sometimes used as writing surfaces in post offices and banks, are too high making it difficult to write anything. Anthropometry deals with the measurements of the human external body dimensions in static and dynamic conditions. Designs without due consideration to the body dimensional requirements of intended users do not serve their purpose and have less user acceptance value. There are numerous medical problems that have resulted because of the use of articles that do not match the anthropometry of the users. Lack of foot space may also be a problem for all workers. In this study the desk height, desk depth, length of desk, chair depth, chair breadth for girls and combined group was noted to be less than required. Inclusive of these dimensions the back rest height and breadth was less than required by the boys, result in uncomfortable feeling and pain due to use of furniture.

- KEY WORDS: Anthropometry, Measurement, Furniture

- HOW TO CITE THIS PAPER : Admankar, Sandhya N. and Sarambekar, H.L. (2015). Teenagers anthropometric measurement and furniture mismatchment. Asian J. Home Sci., 10 (1) : 88-92. 